Office of Safeguards and Security

U.S. Department of Energy

\title{
Review of Androgenic Anabolic Steroid Use
}

\author{
Prepared by \\ T. Borges, Ph.D., MT(ASCP), DABT \\ G. Eisele, Ph.D. \\ C. Byrd, B.S. \\ Center for Human Reliability Studies \\ Oak Ridge Institute for Science and Education \\ Oak Ridge, Tennessee
}

July 2001

ORISE 2001-0933

This document was produced under contract number DE-AC05-00OR22750 between the U.S. Department of Energy and Oak Ridge Associated Universities. 
TABLE OF CONTENTS

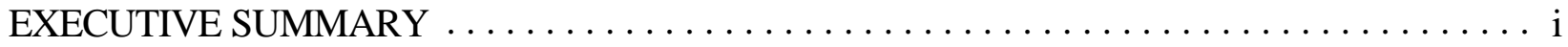

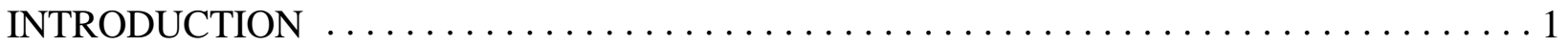

HUMAN STUDIES ON AASs, BEHAVIOR, AND AGGRESSION $\ldots \ldots \ldots \ldots \ldots \ldots \ldots$.

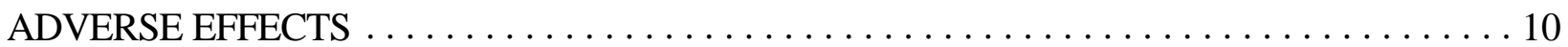

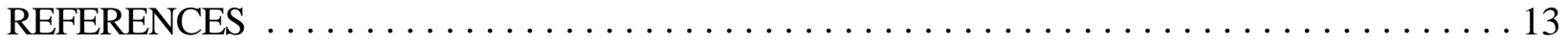

APPENDIX A

PHYSIOLOGICAL FUNCTION OF ANDROGENS $\ldots \ldots \ldots \ldots \ldots \ldots \ldots \ldots$

APPENDIX B

ANIMAL STUDIES ON AASs AND BEHAVIOR $\ldots \ldots \ldots \ldots \ldots \ldots \ldots \ldots \ldots 27$ 


\section{EXECUTIVE SUMMARY}

Since the early 1950s, use of androgenic-anabolic steroids (AAS) has increased as has public awareness of the effects of these drugs. Initially, AASs were used by athletes to increase speed, stamina, and strength. More recently, however, individuals simply dissatisfied with their physiques are reported to be using steroids. Although the effects of increased skeletal muscle and athletic performance may be desirable, the associated physical, psychological, and behavioral side effects are often far more dramatic and potentially damaging.

Endogenously, AASs are responsible for androgenic and anabolic effects that occur during male puberty and adulthood. Because androgens have a significant effect on muscle mass and physical development when administered to hypogonadal men, it is assumed that exogenously derived AASs improve athletic performance. This may be true to a limited extent, but proving an anabolic effect on athletic performance is difficult because such effects are difficult to assess. A slight increase in power or speed might be difficult to document between AAS users and nonusers, but it may have a significant effect on a particular athlete. It has become apparent that whatever, if any, affect AAS use has on athletic performance or appearance, the potential adverse effects on physical and psychological wellbeing must be considered.

The most consistent finding in human and animal studies following AAS use has been increased aggression. In addition, human studies have shown a decrease in tolerance especially in situations involving provocation. These traits in some individuals could result in a potentially violent outburst. While it is true that these effects are not experienced by all AAS users, the increased frequency found in a small, but significant, subpopulation of the estimated one million AAS users in the United States is cause for concern. 
Reports from many studies reveal negative adverse psychological effects from AAS use, especially when the use is prolonged. Such psychological and behavioral effects include changes in mood, behavior, irritability, hostility, anger, and aggression. These effects are becoming so well known that a new name for them has been coined- "roid rage." These effects are even showing up in the court systems where murders are being blamed on prolonged use of AASs. Literature has provided supporting evidence that protective force personnel, such as police officers and security guards, are using AASs on a regular basis. But a more growing concern lies with the average person simply wanting a better-looking physique and an improvement in his or her self esteem. Even before the AntiDrug Abuse Act of 1986 was passed, it was illegal to possess anabolic steroids without a prescription in all 50 states; thus, the only way to purchase AASs was through the rapidly growing black market. With passage of the 1990 Steroid Trafficking Act, steroids were classified as Schedule III controlled substances, and by 1993 persons dealing in them were charged a similar penalty as if they were dealing in cocaine.

The security concern for anabolic steroid use specifically as outlined in Title 10, Code of Federal Regulations, Part 710.8(k), is use of an illegal substance. Because AASs are now listed in Schedule III list of drugs of the Controlled Substances Act, they fall within the same guidelines as use of heroin, cocaine, or any other unlawful drug. The current drug testing program does not include testing for the presence of AASs. As will be discussed later in this paper, the literature dealing with AAS use and behavioral side effects clearly links AAS use to aggressive behavior, violence, and even homicide. And because the criteria for medical use of AASs is extremely limited, the majority of AAS users obtain their supplies from the growing black market. The fact that users are purchasing black market quantities of AAS could allow them to be possibly compromised. Security and safety concerns arise from changes in behavior and mood, such as acting out some hostile thought; reckless behavior; unpredictability; poor impulse control; insomnia; and impaired concentration, and all of these traits have been linked to AAS use. This report brings to the forefront the concerns surrounding AAS use. 
Because the consequences of AAS use can be serious, education of personnel security specialists and employees is critical. As with all drug-prevention programs, early detection and intervention is the key. 


\section{INTRODUCTION}

An area that has been overlooked within personnel security evaluations is employee use of androgenicanabolic steroids (AAS). Current drug testing within the federal government does not include testing for anabolic steroids, and the difficulties to implement such testing protocols—not to mention the cost involved—-make AAS testing highly improbable.

The basis of this report is to bring to the forefront the damage that anabolic steroids can cause from both a physical and a psychological standpoint. Most individuals who use AASs do so to increase their muscle mass because they wish to gain some type of competitive edge during athletic competition or they wish to enhance their physical features for self-satisfaction and self-esteem (i.e., body building). Security officers are one group of men who often take high doses of anabolic steroids, according to the Second Report of the Senate Standing Committee (1990).

The negative psychological characteristics for AAS use is extensive and includes prominent hostility, aggressiveness, irritability, euphoria, grandiose beliefs, hyperactivity, reckless behavior, increased sexual appetite, unpredictability, poor impulse control, mood fluctuations, and insomnia. The drug may invoke a sense of power and invincibility (Leckman and Scahill, 1990). Depressive symptoms, such as anhedonia, fatigue, impaired concentration, decreased libido, and even suicidality (Pope and Katz, 1992) have been noted with steroid withdrawal. It appears that long-term users of AAS experience similar characteristics as other substance abusers (i.e., craving, dependence, and withdrawal symptoms).

Over recent years there have been growing awareness and increased reporting of androgenic-anabolic steroid use by both men and women. AASs are derived from testosterone and were first manufactured synthetically in the 1930s. Legitimate medical uses include treatment for breast cancer, aplastic anemia, 
and edema, as well as promotion of growth in males with delayed puberty and treatment of Turner's syndrome in females (Rogol and Yesalis, 1992a).

The effects of AASs first received public attention in the 1950s when Soviet Olympic weight lifters used synthetic testosterone to gain greater size and strength. This usage spread within the sport and to other strength sports, such as football and track-and-field events. Concern over the perceived performanceenhancing effect of AASs resulted in their being banned by the International Olympic Committee beginning with the 1976 Summer Olympic Games. Successful detection methods for exogenous AAS presence in athletes were introduced in 1983. Unfortunately, AAS use was also detected in 1991 in players of non-strength sports, such as badminton and volleyball. Other users of AASs included high school athletes and some nonsports users who simply wanted to improve their appearance (LaBree, 1991). The significant financial enticement for athletic achievement may lead to ambivalence about AAS use and less stringency of testing.

There are three general classes of AASs: (1) oral steroids, (2) injectable testosterone esters, and (3) nortestosterone derivatives. All are available by prescription but are more commonly found on the black market (Rogol and Yesalis, 1992b). Nonprescribed AAS users structure their doses to maximize the anabolic effects through two processes_- "stacking" and "pyramiding." Stacking is more common and involves taking two or more different steroids by mixing injectable, oral, and illicit veterinary AAS (Brower, 1993). Pyramiding involves starting with a low dose and then slowly increasing the dose of the different steroids. Often the AASs are taken in cycles of 4 to 12 weeks on and 4 to 12 weeks off. Successful bodybuilders often take more than 1,000 times the clinically recommended dose of AASs (Dangle, 1990).

A link between anabolic steroid use and violence already has been documented. At least 20 murders in the United States have been associated with anabolic steroid use (Moss, 1988). Numerous physical assaults also have occurred from which the victim survived. For example, a 32-year-old prison security 
officer became grandiose and paranoid while taking an anabolic steroid and shot a shop assistant in the spine leaving her permanently paraplegic (Williamson, 1994). This is only one example where the perpetrator had no previous psychiatric history or criminal record. "Roid" rages also have been linked to domestic violence and child abuse (Corrigan, 1996).

One of the security concerns for the federal government and its contractors is the potential for employees using AAS to be compromised based on financial needs to purchase AASs and/or lack of knowledge about their use. As discussed later in this paper, even before the passage of the Anti-Drug Abuse Act, it was illegal to possess anabolic steroids without a prescription in all 50 states (Food, Drug and Cosmetic Act of 1938, as amended 21 U.S.C. 301 et seq.). Possession of anabolic steroids is illegal whether or not the steroids are used by humans or animals; therefore, any employee of the federal government or its contractors who uses AASs without a prescription from a licensed physician is committing an illegal act.

Congress passed the Anabolic Steroids Control Act of 1990, which defined anabolic steroids as a controlled substance, placing it into the Controlled Substances Act, Schedule III list of drugs. This act gave enforcement power to the Drug Enforcement Administration and created stiffer penalties for its use, thereby carrying a similar penalty for dealing in them as for dealing in cocaine. To be prosecuted, however, illegal use must be determined. Because of the controls on AASs, most users obtain their supplies through the black market, and the demand for them in recent years is estimated at $\$ 400$ million a year (Rashid, 2000).

The issue for personnel security specialists as well as all coworkers is to become aware of the problem. They must learn to look for such signs as rapid weight gain with a "cut" look to their musculature, mood swings, and an abnormal drive to have a bigger and better appearing body. 
The abuse profile of AAS users is the same as general drug abuse profiles. Unfortunately, with AAS abuse the user also will make arguments of commitment to a sport and the need to be competitive. Evidence of needle sharing and resulting AIDS cases in the AAS population have also been reported (Haupt, 1993; Choi, 1993). Other parallels with the traditional drug-abuse culture include dependence and withdrawal syndromes consistent with the criteria found in the Diagnostic and Statistical Manual of Mental Disorders (DSM-IIIR) (Brower, 1992; Kouri et al., 1994; DuRant et al., 1993; Kashkin and Kleber, 1989; Brower et al., 1991; American Psychiatric Association, 1982). Even though AASs are not physically addicting, there is mounting evidence that supports strong psychological addiction. Individuals using AASs become psychologically addicted to their improved physique, increased strength, and sexual appeal (Swanson et al., 1991). With such positive personal feedback, AAS users will continue using these drugs until they either lose interest in the physical benefits or learn the damaging side effects of AAS use and decide to discontinue them. It has been suggested that a dependence syndrome develops in approximately $14 \%$ to $57 \%$ of cases, but little data to support these percentages were found (Brower et al., 1991). 


\section{HUMAN STUDIES ON AASs, BEHAVIOR, AND AGGRESSION}

Aggressive behavior was investigated in 517 men and 443 women of college age using a self-reporting aggression inventory (Gladue, 1991a). The study revealed that men reported more physical and verbal aggression than women. In a second study (Gladue, 1991b), the relationship of "resting" levels of testosterone and estradiol and self-reported aggressive behavior in heterosexual and homosexual men and women were investigated. Adult men were found to exhibit more physical and verbal aggression than women. Men also had higher scores on measures of impulsiveness and were more intolerant of frustration than women. There were no differences in the responses of homosexual and heterosexual men. Homosexual women differed from heterosexual women with lower scores regarding physical aggression. In the two studies, total testosterone and estradiol (both endogenously derived) were positively correlated with aggressive behavior (physical, verbal, and intolerance) in men but were negatively correlated with women.

The relationship between endogenous testosterone and antisocial behavior was investigated in 4,462 military veterans (Dabbs and Morris, 1990). The average age of the study group was 37 years. It was found that the plasma testosterone concentration correlated with a variety of antisocial behavior and that education and income were moderating factors in the expression of antisocial behavior. Generally, individuals with an advanced education and/or higher incomes exhibited less antisocial behavior than those with lower incomes or less education. Another study (Booth and Dabbs, 1993) revealed that men producing more endogenous testosterone were less likely to marry than were men with lower levels. However, once married, the men with higher testosterone levels were more likely to leave home due to marital problems, have an extramarital affair, or physically or verbally abuse their spouses. In a third study, the relationship between salivary testosterone and cortisol concentrations to personality, criminal violence, prison behavior, and parole decisions of 113 late adolescent male offenders was investigated (Dabbs et al., 1991). Individuals with high salivary testosterone levels were found to commit more violent crimes, disregard prison rules, and were judged more harshly by parole boards 
than those individuals with lower salivary testosterone levels. It was also found that plasma cortisol may be a moderating factor with the correlation between testosterone and violence. As cortisol levels increased, the correlation between testosterone and violence decreased. This would suggest that cortisol may be a biological indicator of psychological variables moderating testosterone and behavior. A more recent study by Dabbs et al., (1995) revealed that prison inmates who committed personal crimes of sex and violence had higher testosterone levels than inmates who committed burglary or were involved with drugs. Of the 692 male inmates studied, those with higher testosterone levels violated more prison rules, particularly those involving confrontation.

In contrast to these studies, however, no relationship between violent behavior and serum testosterone, cortisol, glucose, or alcohol levels was found in 16 men taken into custody for spousal abuse when compared to nonviolent men (Lindman et al., 1992). Likewise, there was no apparent systematic relationship between aggression and testosterone level in 100 adolescent and pubescent males (Halpern et al., 1993).

Numerous studies have investigated the effect of exogenous AAS use and reported similar findings. Only a sample of these studies will be reported here. Three men who impulsively committed violent crimes, including murder, were taking anabolic steroids at the time (Pope and Katz, 1990). Structured psychiatric interviews of the men suggested that AAS played a role in their behavior. In another instance, a 20-year-old man committed armed robbery after taking low doses of AAS (Dalby, 1992). The individual reported he had been irritable, depressed, and subject to violent rages following a fiveweek cycle of self-administered Equipoise (starting with $0.5 \mathrm{~mL}$ administered four times per week and increasing the dose $0.5 \mathrm{~mL}$ each week). It was concluded in his trial that AAS use was a mitigating factor in the crime. In another case, a 19-year-old male college football player who had been stacking intramuscular testosterone with oral methandrostenolone over a four-month period physically abused his two-year-old child and wife (Schulte et al., 1993). Prior to this time, no previous AAS use or violent behavior had been reported. When using AAS, however, the male became increasingly irritable 
with his wife physically, verbally, and sexually, as well as more impatient with the child. After cessation of AAS use, the male's physical and mental behavior returned to normal, and no further violent behavior occurred.

A study of 138 male body builders was conducted to determine the prevalence of AAS use and the relationship between health risks, social backgrounds, and economic status (Lindstrom et al., 1990). The study revealed that $38 \%$ of the body builders used AAS, and of these $81 \%$ had experienced altered behavioral characteristics such as mood changes or increased libido. AAS users also were found to be more knowledgeable about AAS use than nonusers. In another study of athletic male users of AAS, the Buss-Durkee Hostility Inventory (BDHI) was administered to 21 individuals (Parrott et al., 1994). This study revealed that AAS users had significantly higher levels of aggression toward objects, verbal aggression, aggressiveness while training, irritability, and anxiety. However, when the men stopped using exogenous AASs, these traits disappeared.

Similar behavioral traits were reported in a group of 22 former male track athletes (Silvester, 1995). Among the effects noted, $59 \%$ of the athletes reported an increase in aggressiveness and irritability, $45 \%$ had distinct feelings of well-being, and $23 \%$ perceived quicker recovery from workouts following AAS use. Only two of the athletes thought their increased aggressiveness or irritability away from training was a result of AAS use.

The effect of long-term AAS use with doses of 50 to $100 \mathrm{mg} /$ day was studied in three male weight lifters using the BDHI, Mood States questionnaire, and the Rosenweig Picture Frustration Test (Choi et al., 1990). The results were compared to three weight lifters who did not use AASs. It was reported that the three AAS users were significantly more aggressive than nonusers, but these traits disappeared during periods that the athletes were not using AASs. It was also reported that when using AASs, the athletes were more violent and were significantly more verbally aggressive toward women. 
The effects of chronic treatment with testosterone cypionate on aggressive behavior were assessed using the Point Subtraction Aggression Paradigm (PSAP) in a group of nonsteroid users (Kouri et al., 1995). Eight individuals were randomized to one of two treatment regimes: (1) $600 \mathrm{mg} / \mathrm{week}$ intramuscular testosterone for six weeks, no treatment for six weeks, placebo injections for six weeks, and no treatment for six weeks or (2) placebo injections for six weeks, no treatment for six weeks, testosterone injections for six weeks, and no treatment for six weeks. The individuals were tested before starting the study to establish a baseline and at one week after the last injection of testosterone or placebo. The number of aggressive responses was significantly higher after testosterone treatment than when the subjects were treated with the placebo. However, there were no differences in the number of nonaggressive responses before or after testosterone treatment. It should also be noted that the PSAP was significantly increased after testosterone.

A two-week, double-blind, fixed order, placebo-controlled study was done to evaluate the neuropsychiatric effects of methyl-testosterone on 20 nonsteroid-using male volunteers (Su et al., 1993). The subjects received a sequential three-day trial of a placebo, $40 \mathrm{mg} /$ day of testosterone, 240 $\mathrm{mg} /$ day of testosterone, followed again by the placebo. During high-dose testosterone administration, the men reported significant increases in euphoria, energy, sexual arousal, irritability, hostility, violent moods, and cognitive impairment. During the study, one participant had an acute manic episode while another became hypomanic. Both of these occurred while the subjects were receiving high-dose testosterone. These results suggest that methyl-testosterone has a significant impact on mood and behavior, even after short-term administration.

As mentioned, numerous studies have investigated the effect of exogenous AASs on males and females, and most all report an increase in aggressiveness and alteration of behavior. Although an apparent link exists between exogenous testosterone use and aggression, particularly in males, recent literature has reported that estrogen, and not testosterone, may be responsible (Ogawa, et al., 1995). This theory has been studied because testosterone is aromatized to estrogen, which in turn can have a direct effect 
on the brain. Evidence to support this theory comes from two studies—one conducted with mice and one with humans. In the first study, behavioral results on the loss of functional estrogen receptors in male estrogen receptor knockout mice were investigated (Ogawa et al., 1995). The study showed that the lack of estrogen receptors in the central nervous system modified male emotional behavior, thereby making the mice less susceptible to steroid-induced aggression. This indicates the importance of estrogen receptors for increasing aggression following AAS treatment.

A double-blind, placebo-controlled, three-month study was conducted to investigate the effects on behavior and aggression of depo-testosterone or estrogen in hypogonadal boys or girls (Finkelstein et al., 1995). The results were evaluated using the Olweus Multifaceted Aggression Inventory. At low doses, aggressive responses and actual physical aggression against peers was significantly increased only for girls. At mid-dose levels, the scores for girls significantly increased for these same traits. In addition, both boys and girls had increased physical aggression toward adults. At the highest dose, physical aggression against peers was increased only for boys. The results suggest that steroids can influence aggressive behavior in adolescents. In addition, because the girls showed earlier and greater increases in aggression than boys, it is possible that excessive estrogen plays a major role in the development of aggression and that testosterone may contribute to this response through its conversion to estrogen. While circulating levels of estrogen in males is normally low, any increase as seen following AAS use may have profound effects. Because estrogen in the plasma crosses the blood-brain barrier, increased activation as a result of a higher circulating estrogen level may contribute to the aggressiveness and other behavioral changes seen in males following AAS use. 


\begin{abstract}
ADVERSE EFFECTS
The desired physical effect of AAS use is to increase the synthesis of protein in skeletal muscle, promote nitrogen retention, and increase lean body mass. This is especially true in experienced weight trainers when they are doing high-intensity work combined with high-protein diets (Lombardo, 1992; Kuipers et al., 1991). But when AASs are abused, three types of side effects are typically found:

1. Inappropriate virilizing side effects in nonhypogonadal adult men

2. Feminizing side effects mediated by estrogenic metabolites of administered steroid

3. Toxic side effects mediated by unknown mechanisms.
\end{abstract}

When used in women, all AASs carry the risk of causing masculinization. Among the undesirable manifestations are acne, growth of facial hair, and coarsening of the voice. Menstrual irregularities will occur if gonadotropin secretion is suppressed by AAS administration. If treatment is discontinued as soon as the initial symptoms are noticed, these effects will slowly subside. With continued treatment, such as long-term use of androgen therapy in mammary carcinoma, male-pattern baldness, excessive body hair, prominent musculature, and hypertrophy of the clitoris may develop. In some instances, it was found that these side effects were irreversible.

Profound virilization and serious disturbances of growth and osseous development can occur when androgens are given to children. The capacity of androgens to increase epiphyseal closure in children may persist for as long as several months after discontinuation of AAS treatment. In addition, bone and tendons are unaffected by AAS treatment, and as a result they can be torn or broken due to the strength of the increased muscle mass. Therefore, androgens should be used with great care in children and should not be used at all during pregnancy because they can cross the placental barrier and induce skeletal effects and masculinize a female fetus. 
Androgens are required for spermatogenesis and may maintain spermatogenesis for extended periods in animals after hypophysectomy. However, prolonged use of exogenous AASs in normal men markedly decreases the sperm count owing to inhibition of gonadotropin secretion and conversion of androgens to estrogens. This effect can persist for many months after administration of AASs has stopped (Lloyd et al., 1996).

Feminizing side effects, particularly gynecomastia, can occur in men who receive high doses of exogenous androgen. This is particularly true when the androgen contains or is metabolized to a $\ddot{A}^{4}, 3$ keto configuration since this can be further aromatized to estrogen. In humans peripheral aromatization of AASs to estrogens is an important source of circulating estrogens, and up to $30 \%$ to $40 \%$ of extragonadal aromatization occurs in the muscle and adipose tissue (Longscope et al., 1978). The feminizing side effects are particularly severe in children and men with liver disease. Other toxic side effects associated with AAS administration include edema associated with the retention of sodium and chloride, jaundice from cholestatic hepatitis, and hepatic carcinoma (Kopera, 1993).

Androgens are also thought to be responsible, at least in part, for the aggressive and sexual behavior of males and for organizational effects in the brain during prenatal or early postnatal life (Bahrke et al., 1990 and 1996; Lukas, 1996; Wilson, 1982; Rubinow and Schmidt, 1996). While psychopathic behavior in men is not associated with altered patterns of androgen metabolism, administration of AASs to normal virile men for short periods can cause a variety of adverse effects on mood and behavior (Su et al., 1993). Therefore, the differential behavior patterns of males and females suggest that sex hormones play an important role in behavior.

The adverse effects of AAS use from a behavioral or psychological standpoint is the area that should attract the attention of the personnel security specialist. It is widely known that aggressive behavior is almost universal among anabolic steroid users (Charlier, 1988). Psychological changes that occur from 
prolonged steroid use can be divided into three groups, representing a continuum of effects—-from mild to severe-for the prolonged use of high doses.

1. Early effects are seen as changes in mood and euphoria. There are increased confidence, energy, and self-esteem with enhanced motivation and enthusiasm. There are also diminished fatigue, sleeplessness, and an ability to train through pain. Libido may be decreased, but it is more often increased, sometimes to a marked degree (Moss et al., 1993). Irritability, anger, agitation, and a strange, edgy feeling are commonly reported.

2. With larger doses or after taking AASs for a longer time, there is a loss of inhibition and a lack of judgment with mood swings and grandiose ideas. With prolonged use, individuals become suspicious, quarrelsome, impulsive, and more aggressive (Lombardo et al., 1992).

3. Several effects manifest when these aggressive feelings increase to the extent that violent, hostile, antisocial behavior develops, meriting the descriptive title, well known in the steroidtaking community of "roid rages." This term was coined to describe the explosive and often irrational behavior seen in men and women who use anabolic steroids (especially those that are highly androgenic) on a regular basis and above therapeutic dosages (Occhipinti, 1997). These rages can result in property damage, self-injury (including reckless driving or crashing cars), assaults, marriage breakups, domestic violence, child abuse, suicide, and attempted murder or murder. In fact, at least 20 murders associated with the use of AASs have been reported in America (Moss, 1988). 


\section{REFERENCES}

American Psychiatric Association. (1982). Diagnostic and statistical manual of mental disorders, 3rd ed., revised. Washington, DC: APA.

Bahrke M.S., Yesalis C.E., Wright J.E. (1990). Psychological and behavioral effects of endogenous testosterone levels and anabolic-androgenic steroids among males. Sports Med, 10:303-337.

Bahrke M.S., Yesalis C.E., Wright J.E. (1996). Psychological and behavioral effects of endogenous testosterone levels and anabolic-androgenic steroids among males. An update. Sports Med, 22:367-390.

Behre H.M., Nieschlag E. (1992). Testosterone buciclate (20 Aet-1) in hypogonadal men: Pharmacokinetics and pharmacodynamics of the new long-acting androgen ester. J Clin Endocrinol Metab, 75:1204-1210.

Bing O., Heilig M., Kakoulidis P., et al. (1998). High doses of testosterone increase anticonflict behavior in rat. Eur Neuropsychopharm, 8:321-323.

Booth A., Dabbs J. (1993). Testosterone and men’s marriages. Soc Forces, 72:463-477.

Bronson F., Nguyen K., De La Rosa J. (1996). Effect of anabolic steroids on behavior and physiological characteristics of female mice. Physiol Behav, 59:49-55.

Brower K.J., Blow F.C., Young J.P., et al. (1991). Symptoms and correlates of anabolic-androgenic steroid dependence. Br J Addict, 86:759-768.

Brower K.J. (1992). Clinical assessment and treatment of anabolic steroid users. Psychiatr Ann, 22:35-40.

Brower K.J. (1993). Anabolic steroids. Psychiatr Clin North Am, 16(3):97-103.

Charlier, M. (1988). For teens, steroids may be bigger issues than cocaine use. Wall Street Journal, Oct. 4.

Choi P.Y.L., Parrott A.C., Cowan D. (1990). High-dose anabolic steroids in strength athletes: Effects upon hostility and aggression. Hum Psychopharmacol, 5:349-356. 
Choi P.Y.L. (1993). Alarming effects of anabolic steroids. Psychologist, 6:258-260.

Clark A., Barber D. (1994). Anabolic-androgenic steroids and aggression in castrated male rats. Physiol Behav, 56:1107-1113.

Clark A., Lindenfield R., Gibbons C. (1996). Anabolic-androgenic steroids and brain reward. Pharmacol Biochem Behav, 53:741-745.

Corrigan, B. (1996). Anabolic steroids and the mind. MJA, 165:222-226.

Dabbs J., Morris R. (1990). Testosterone, social class, and antisocial behavior in a sample of 4462 men. Psychol Sci, 1:209-211.

Dabbs J., Jurkovic G., Frady R. (1991). Salivary testosterone and cortisol among late adolescent male offenders. J Abnorm Child Psychol, 19:469-478.

Dabbs J., Carr T., Frady R., et al. (1995). Testosterone, crime, and misbehavior among 692 male prison inmates. Person Individ Diff, 18:627-633.

Dalby J. (1992). Brief anabolic steroid use and sustained behavioral reaction. Am J Psychiatry, 149:271-272.

Dangle R.D. (1990). Anabolic steroids. J Psychoactive Drugs, 22:77-80.

DuRant R.H., Rickert V.I., Ashworth C.S., et al. (1993). Use of multiple drugs among adolescents who use anabolic steroids. N Engl J Med, 328: 922-925.

Feinberg M.J., Lumia A.R., McGinnis M.Y. (1997). The effect of anabolic-androgenic steroids on sexual behavior and reproductive tissues in male rats. Physiol Behav, 62:23-30.

Finkelstein J., Susman E., Chinchilli V., et al. (1995). Testosterone or conjugated estrogen cause increases in aggressive behavior in hypogonadal boys or girls (abstract). $77^{\text {th }}$ Annual Meeting of the Endrocrine Society.

Findlay J.K., Clarke I.J., Luck M.R., et al. (1991). Peripheral and intragonadal actions of inhibinrelated peptides. J Reprod Fertil, 43 (suppl.):139-150.

Forbes G.B., Porta C.R., Herr B.E., Griggs R.C. (1992). Sequence of changes in body composition induced by testosterone and reversal of changes after drug is stopped. JAMA, 267:397-399. 
Fotherby K., James F. (1972). Metabolism of synthetic steroids. Adv Steroid Biochem Pharmacol, 3:67-165.

Gladue B. (1991a). Qualitative and quantitative sex differences in self-reported aggressive behavioral characteristics. Psychol Rep, 68:675-684.

Gladue B. (1991b). Aggressive behavioral characteristics, hormones, and sexual orientation in men and women. Aggressive Behav, 17:313-326.

Griggs R.C., Kingston W., Jozefowicz R.F., et al. (1989). Effect of testosterone on muscle mass and muscle protein synthesis. J Appl Physiol, 66:498-503.

Halpern C., Udry J., Campbell B., et al. (1993). Relationship between aggression and pubertal increases in testosterone: A panel analysis of adolescent males. Soc Biol, 40:8-24.

Haupt H.A. (1993). Anabolic steroids and growth hormone. Am J Sports Med, 21:468-474.

Kashkin K.B., Kleber H.D. (1989). Hooked on hormones? An anabolic steroid addiction hypothesis. JAMA, 262:3166-3170.

Knowlton K., Kenyon A.T., Sandiford I., Lotwin G., Fricker R. (1942). Comparative study of metabolic effects of estradiol benzoate and testosterone propionate in man. J Clin Endocrinol Metab, 2:671-684.

Kochakian C.D., Murlin J.R. (1935). The effect of male hormone on the protein and energy metabolism of castrated dogs. J Nutr, 10:437-459.

Kopera H. (1993). Side effects of anabolic steroids and contraindications. Wien Med Wochenschr, 143:14-15.

Kouri E.M., Pope H.G., Katz D.L. (1994). Use of anabolic steroids: We are talking prevalence rates. JAMA, 271:347.

Kouri E.M., Lukas S.E., Pope H.G., Oliva P.S. (1995). Increased aggressive responding in male volunteers following the administration of gradually increasing doses of testosterone cypionate. Drug and Alcohol Depend., 40:73-79.

Kuipers H., Wijnen J.A.G., Hergens F., et al. (1991). Int J Sports Med, 12:413-418.

LaBree M. (1991). A review of anabolic steroids: Uses and effects. J Sports Med Phys Effects, 31:618-626. 
Leckman, J.F., and Scahill, L. (1990). Possible exacerbation of tics by androgenic steroids. New England J Med 322:1674.

Lindman R., von der Pahlen B., Ost B., et al. (1992). Serum testosterone, cortisol, glucose, and ethanol in males arrested for spouse abuse. Aggressive Behav, 18:393-400.

Lindstom M., Nilsson A.L., Katzman P.L., et al. (1990). Use of anabolic-androgenic steroids among bodybuilders-Frequency and attitudes. J Intern Med, 227:407-411.

Lloyd F.H., Powel P., Murdoch A.P. (1996). Lesson of the week: Anabolic steroid abuse by body builders and male subfertility. BMJ, 313:100-101.

Lombardo J.A. (1992). Anabolic-androgenic steroids. Natl Inst Drug Abuse Res Monogr Ser, 102:60-73.

Longscope C., Pratt J.H., Schneider S.H., Fineberg S.E. (1978). Aromatization of androgens by muscle and adipose tissue in vivo. J Clin Endrocrinol Metab, 46:146-152.

Lukas S.E. (1996). CNS effects and abuse liability of anabolic-androgenic steroids. Annu Rev Pharmacol Toxicol, 36:333-357.

Lumia A.,Thorner K., McGinnis M. (1994). Effects of chronically high doses of the anabolic androgenic steroid, testosterone, on intermale aggression and sexual behavior in male rats. Physiol Behav, 55:331-335.

Marcus R., Korenman S.G. (1976). Estrogens and the human male. Annu Rev Med, 27:357- 370.

Matsumoto A.M., Bremner W.J. (1984). Modulation of pulsatile gonadotropin secretion by testosterone in man. J Clin Endocrinol Metab, 58:609-614.

Minkin D., Meyer M., vaan Haaren F. (1993). Behavioral effects of long-term administration of an anabolic steroid in intact and castrated male Wistar Rats. Pharmacol Biochem Behav, 44(4):959-963.

Ogawa S., Luban D., Korach K., et al. (1995). Behavioral characteristics of transgenic estrogen receptor knockout male mice: Sexual aggressive and open-field behaviors (abstract). $77^{\text {th }}$ Annual Meeting of the Endrocrine Society.

Parrott A., Choi P., Davies M. (1994). Anabolic steroid use by amateur athletes: Effects upon psychological mood states. J Sports Med Phys Fitness, 34:292-298. 
Parthridge W.M., Gorski R.A., Lippe B.M., Green R. (1986). Androgens and sexual behavior. Ann Intern Med, 96:488-501.

Pope H.G., Katz D.L. (1990). Homicide and near-homicide by anabolic steroid users. J Clin Psychiatry, 51:28-31.

Pope, H.G., and Katz, D. L. (1992). Psychiatric effects of anabolic steroids. Psytchiatr Ann 22:24-29.

Ramasharma K., Sairam M.R. (1982). Isolation and characterization of inhibin from human seminal plasma. Ann NY Acad Sci, 383:307-328.

Rashid M.D., Wasim (2000). Testosterone abuse and affective disorders. Journal of Substance Abuse Treatment 18:179-194.

Rejeski W.J., Bruebaker P.H., Herb R.A., et al. (1988). Anabolic steroids and aggressive behavior in cynomolgus monkeys. J Behav Med, 11:958-1005.

Rejeski W.J., Gregg E., Kaplan J.R., et al. (1990). Anabolic-androgenic steroids: Effects on social behavior and baseline heart rate Health Psychol, 9:774-791.

Rogol A.D., Yesalis C.E. (1992b). Anabolic-androgenic steroids and the adolescent. Pediatr Ann, 21:175-188.

Rubinow D.R., Schmidt P.J. (1996). Androgens, brain, and behavior. Am J Psychiatry, 153:974-984.

Saartok T., Dahlberg E., Gustafsson J.A. (1984). Relative binding affinity of anabolic-androgenic steroids: Comparison of the binding to the androgen receptors in skeletal muscle and in prostate, as well as to sex hormone-binding globulin. Endrocrinol, 114:2100-2106.

Schulte H., Hall M., Boyer M. (1993). Domestic violence associated with anabolic steroid abuse. Am J Psychiatry, 150:348.

Second Report of the Senate Standing Committee (Chairman John Black). (1990). Drugs in Sport. Canberra: AGPS, 357-368.

Shally A.V. (1978). Aspects of hypothalamic regulation of the pituitary gland: Its implications for the control of reproductive processes. Science, 202:18-28.

Silvester L. (1995). Self-perceptions of the acute and long-range effects of anabolic-androgenic steroids. J Strength Conditioning Res, 9:95-98. 
Su T-P., Pagliaro M., Schmidt P.J., et al. (1993). Neuropsychiatric effects of anabolic steroids in male normal volunteers. JAMA, 269:2760-2764.

Swanson C.R., Gaines, L., Gore, B. (1991). Abuse of anabolic steroids. FBI Law Enforcement Bulletin, 60(8):19-23.

Van Wayjen R.G. (1993). Metabolic effects of anabolic steroids. Wien Med Wochenschr, 143:1415.

Williamson, D. (1994). The psychological effects of anabolic steroids. Int J Drug Pol, 5(1).

Wilson J.D. (1982). Gonadal hormones and sexual behavior. Clin Neuroendocrin, II:1-19.

Wilson J.D. (1988). Androgen abuse by athletes. Endocr. Rev, 9:181-199.

Wilson J.D., Griffin J.E. (1980). The use and misuse of androgens. Metabolism, 29:1278-1295.

Wu F.C. (1997). Endorcrine aspects of anabolic steroids. Clin Chem, 43:1289-1292.

Yesalis C.E. (1992). Epidemiology and patterns of anabolic-androgenic steroid use. Psychiatr. Ann., 22:7-18. 
APPENDICES 


\section{APPENDIX A PHYSIOLOGICAL FUNCTION OF ANDROGENS}

Testosterone is the primary natural male hormone responsible for androgenic (masculinizing) and anabolic (tissue building) effects observed during puberty and adulthood. It is secreted from the testes and is the main androgen or male sex hormone found in the plasma of men although the plasma of women also contains small amounts secreted from the ovaries and the adrenal gland. In most target tissues, testosterone is reduced at the 5á position to dihydrotestosterone, which serves as the primary intracellular mediator of most androgenic hormonal actions. Dihydrotestosterone binds to the intracellular receptor more tightly than testosterone and as a result has greater androgenic potency. Other additional weak androgens exist and include the testosterone precursor androstenedione, the adrenal androgen dehydroepiandosterone, the dihydrotestosterone metabolite 5á-androstane-3á-17â-diol, and androsterone. However, these steroids bind weakly to the androgenic receptor, and it is unlikely they act directly as hormones at physiological concentrations and act as androgens only to the extent that they are converted to testosterone and/or dihydrotestosterone in vivo. The major metabolites of androgens in urine, both free steroids and water-soluble conjugates, are physiologically weak or inactive. Testosterone can be aromatized to estradiol in a variety of extraglandular tissues, a pathway that accounts for most of the estrogenic synthesis in men and postmenopausal women. Either the relative or absolute excess synthesis of estrogen in men in this manner induces feminization.

The concentration of testosterone in males is relatively high during three periods of life: (1) during embryonic development while the male phenotypic differentiation is occurring, (2) the neonatal period, and (3) throughout the adult sexual life. Testosterone concentration begins to rise in male embryos about the eighth week of development and then rapidly declines just before birth. It rises briefly again during the neonatal period before falling to prepubertal levels within the first year of life. At the onset of male puberty, the pituitary begins to secrete increased amounts of the gonadotropin luteinizing hormone (LH) and follicle-stimulating hormone (FSH). Although gonadotropins are initially secreted in a cyclic 
fashion in synchrony with the sleep cycle, as puberty progresses, pulsatile secretion of gonadotropins occurs during both the sleep and waking periods. Additionally, the hypothalamus and pituitary become less sensitive to feedback inhibition by sex hormones during puberty. The initiating event for these phenomena is unknown.

Before puberty, concentrations of testosterone in plasma are low $(<20 \mathrm{ng} / \mathrm{dL})$ although the immature testes can synthesize androgens if challenged with gonadotropin. In the adult male, plasma testosterone concentrations are typically between 300 and $1000 \mathrm{ng} / \mathrm{dL}$ with a production of 2.5 to $11 \mathrm{mg} / \mathrm{day}$. Approximately $40 \%$ of testosterone is bound to sex hormone-binding globulin in the plasma, and about $2 \%$ is free; the remainder is bound to albumin and other proteins. Albumin-bound testosterone can dissociate within capillary beds such that the fraction available for rapid entry into cells is actually about half the total available (Parthridge et al., 1986).

In adult men, the plasma concentrations of $\mathrm{LH}, \mathrm{FSH}$, and testosterone fluctuate during the day although integrated daily values remain relatively constant. LH and FSH together regulate testicular growth, spermatogenesis, and steroidogenesis. Additionally, growth hormone (GH) may have a synergistic effect with LH on the testes, while estrogens can decrease the effects of $\mathrm{LH}$ on testosterone secretion. In the testes, LH interacts with the interstitial (Leydig's) cells to increase the synthesis of cyclic aminomonophosphate (AMP) and the subsequent conversion of cholesterol to androgens. Cyclic AMP also enhances the activity of several enzymes in the steroidogenic pathway, including cholesterol side chain cleavage, and it may influence the availability of cholesterol to serve as a substrate.

The major action of FSH is promotion of spermatogenesis in the seminiferous tubules while LH regulates testosterone synthesis by the Leydig's cells. FSH also can augment the activity of LH and enhance testosterone synthesis required for spermatogenesis and maturation of sperm. While androgens released from the interstitial cells diffuse into the spermatogenic tubule and promote spermato- 
genesis, they also gain access to the circulation and virilize the male at puberty (Matsumoto and Bremner, 1984). Both LH and FSH have growth-promoting effects on the testes.

Administration of testosterone to intact animals can suppress the secretion of LH and thereby induce interstitial tissue atrophy (Feinberg et al., 1997). Exogenous testosterone also can suppress excessive secretion of FSH in eunuchism, but whether testosterone plays a major role in the physiological regulation of FSH secretion is unknown. Implantation of testosterone in the median eminence of rats has been shown to inhibit pituitary gonadotropin secretion by decreasing the concentration of gonadotropin-releasing hormone (GnRH) (Shally, 1978). Likewise, the administration of testosterone to hypogonadal men will cause a decrease in both the frequency and amplitude of LH secretion, presumably by inhibiting the release of GnRH (Matsumoto and Bremner, 1984).

Approximately $15 \%$ of the estradiol is secreted from the testes in normal men-most likely from the Leydig's cells. Estrogens are also synthesized in men from androgens in extraglandular tissues, including the brain (Marcus and Korenman, 1976). Estrogens formed locally in the brain from administered or endogenous androgens are believed to function in regulation of gonadotropin secretion by testosterone.

Feedback inhibition of FSH secretion by testicular hormones involves peptides as well as steroids (Ramasharma and Sairam, 1982). The polypeptide hormone inhibin, synthesized by the testicular Sertoli's cells and also in the ovaries, is believed to decrease production of mRNA for the â-subunit of pituitary FSH, thereby regulating its secretion (Findlay et al., 1991).

As mentioned, androgens serve different functions at different stages of life. During embryonic life, they virilize the urogenital tract of the male embryo; essential for the development of the male phenotype. During the neonatal phase of life, the role of androgens has not been well elucidated, but they may be involved with developmental functions within the central nervous system. At puberty, however, the 
primary function of androgenic hormones is to transform the boy into a man. Before puberty, minimal androgen secretion from the prepubertal testes and adrenal cortex suppresses gonadotropin secretion. At puberty, however, the secretion of gonadotropins becomes less sensitive to feedback inhibition, and the testes begin to enlarge. Simultaneously, the growth-promoting property of the androgens causes an increase in height and development of the skeletal musculature. Before puberty is completed, the testes will have reached adult size; the skin will have become thicker and oilier from the proliferation of sebaceous glands; subcutaneous fat will have been lost; the veins will have become more prominent under the skin; and axillary hair and hair on the trunk and limbs will have developed into a typical male pattern.

When administered in the clinical situation, testosterone injected as a solution in oil is absorbed, metabolized, and excreted so quickly that the androgenic effect is minimal. When given orally, testosterone is readily absorbed but is even less effective than the injected hormone since most of it is absorbed into the portal circulation and metabolized by the liver before reaching the systemic circulation. However, testosterone esters are less polar than the free steroid and when injected intramuscularly are absorbed more slowly. As an example, testosterone propionate is more physiologically active than testosterone when injected intramuscularly. Testosterone cypionate and enanthate esters are fully effective when given at 1- to 3-week intervals in proportionately larger doses. The ultra-long-acting ester buciclate can be administered at 12-week intervals (Behre and Nieschlag, 1992).

Testosterone is inactivated primarily in the liver. Metabolism involves oxidation of the 17-hydroxy group to form androstenedione. The 5á reduction of the A-ring of androstenedione leads to the formation of androstenedione, which is further reduced at the 3-keto position to form androsterone. Alternatively, androstenedione can be reduced in the 5â position and with further 3-keto reduction form etiocholanolone. Dihydrotestosterone, the active metabolite of testosterone, is converted in the liver to androsterone, androstanedione, and androstanediol (Fotherby and James, 1972). Alkylation of 
androgens at the 17 position retards their hepatic metabolism, allowing for such analogs to be more effective orally. Following administration of radiolabeled testosterone, approximately $90 \%$ of the radioactivity appears in the urine as androsterone and etiocholanolone with $6 \%$ in the feces after having undergone enterohepatic circulation. In addition, small amounts of androstanediol and estrogens as glucuronide or sulfate conjugates are also excreted.

The in vivo anabolic (nitrogen-retaining) effects of androgens were first demonstrated in castrated dogs (Kochakian and Murlin, 1935). When testosterone was administered to female or castrated male dogs, it induced male-like muscle development, thereby indicating muscle development is a phenotypic characteristic dependent upon androgen for expression. In humans the major differences in skeletal muscle development between the sexes after puberty are in the muscles of the shoulder girdle where they are more developed and larger in the virile male. In these tissues, the anabolic actions of androgens are mediated by the same receptor protein that mediates the actions of the hormones in other tissues (Saartok et al., 1984). However, the effects of androgen administration to humans are more pronounced in women, prepubertal boys, and hypogonadal men than they are in normal men (Knowlton et al., 1942). In normal men, administration of pharmacological amounts of androgen induces only a very slight and transient positive nitrogen balance. In hypogonadal men, however, a 25mg daily dose of testosterone propionate causes a pronounced retention of nitrogen, potassium, sodium, chloride, phosphate, and sulfur. There is also weight gain resulting from water retention due to the retained electrolytes and protein. On cessation of testosterone treatment, sodium, chloride, and water are quickly lost; phosphate and potassium decline somewhat less rapidly and completely; and the stored nitrogen is retained for weeks (Wilson and Griffin, 1980).

Because androgens have significant effects on muscle mass and on body weight when administered to hypogonadal men, it was assumed that androgens could promote growth of muscle above the levels produced by normal testicular secretion. This assumption was based on the belief that anabolic and androgenic actions were different, and a concerted effort was made to devise purely "anabolic" steroids 
that had no androgenic effect. In fact, however, androgenic and anabolic effects do not result from different actions of the same hormone but represent the same action in different tissues. Androgenresponsive muscle contains the same receptors that mediate the action of the hormone in other target tissues, and all synthetic and natural anabolic hormones tested to date have androgenic effects (Saartok et al., 1984).

Androgens have also been used by athletes in the belief that performance will be improved. Weight lifters and bodybuilders began to use AASs in the 1950s, and androgen abuse subsequently became widespread at all levels of athletic competition. Indeed, the problem is growing in magnitude and has received a great deal of attention in the press. Unfortunately, many athletes who abuse androgens, including those who use veterinary drugs not approved for human use, obtain them through the "steroid underground." Just as worrisome are the athletes that obtain steroids legally from physicians even though the long-term aspects of androgen abuse are not understood.

Androgens do promote muscle growth in boys and in women of all ages. However, it is not known whether androgens have any beneficial effect on muscle development, nitrogen balance, or athletic performance in sexually mature men. Appropriately controlled studies on the effects of androgens on strength and performance in conditioned athletes have yielded inconclusive results. If androgens do have a beneficial effect, it is not known how they would work since the androgen receptors in mature men are functionally saturated. However, massive doses of androgen have been shown to enhance lean body mass and increase whole-body protein synthesis (Forbes et al., 1992; Griggs et al., 1989; van Wayjen, 1993). It is possible that the AASs inhibit the catabolic effects of glucocorticoids at the level of the glucocorticoid receptor (Wilson, 1988; Wu, 1997).

Proving androgens affect athletic performance in men is not easy. First, the side effects of the megadoses taken by athletes are typically so pronounced as to preclude efficacy in truly blind studies. Secondly, only a small subset of users may have a beneficial response, which makes it difficult to 
identify the rare responders. Finally, effects on athletic performance become more difficult to assess as the caliber of athlete increases. For example, a $1 \%$ to $3 \%$ difference in power or speed might be difficult to document between AAS users and nonusers but might make a significant performance contribution to a particular athlete. As a consequence, many athletes, coaches, and sport physicians are convinced that the agents do enhance athletic performance. This has resulted in shifting emphasis on AAS education to mandatory drug testing in organized sports. 


\section{APPENDIX B}

\section{ANIMAL STUDIES ON AASs AND BEHAVIOR}

Several studies have investigated the relationships between AASs, dominance, and aggressive behavior in various animal species. In one study, the effect of AAS on behavior, baseline heart rate, and stressinduced heart rate of cynomolgus monkeys assigned to one of four social groups was investigated (Rejeski et al., 1990). Treated monkeys received $4 \mathrm{mg} / \mathrm{kg}$ testosterone propionate every week for 8 weeks and $2 \mathrm{mg} / \mathrm{kg}$ testosterone cypionate every week for two weeks. Control animals were included in the study and they received sesame oil. It was found from this study that hormone administration resulted in increases of dominant behavior in dominant animals and increased submission in subordinate animals. Eight weeks after the last treatment, behavior patterns returned to pretreatment activities. Affiliated behavior, such as grooming and body contact, did not return to pretest levels during the eightweek recovery period, suggesting that exogenous testosterone administration has a lasting effect.

One study investigated what effects eight weeks of nandrolone decanoate treatment had on normal and castrated male rats. It was found that AAS treatment increased body weight, kidney size and weight, and testes weight in both types of male rats but also decreased locomotor activity (Minkin et al., 1993). Another study, also conducted with rats, investigated the long-term exposure effect of high doses of testosterone propionate on intact male rats. This study showed that AAS did not alter male copulatory response, but male rats receiving AASs were significantly more dominant and less submissive than intact control male rats (Lumia et al., 1994).

Clark and Barber (1994) investigated the aggression-inducing properties of two anabolic steroids - stanozolol and methyl testosterone - using castrated male rats. Rats treated with $3 \mathrm{mg} / \mathrm{day}$ subcutaneous methyl testosterone displayed levels of aggression significantly greater than rats treated with $400 \mathrm{Fg}$ /day stanozolol. It should also be noted that neither treatment group developed locomotor activity problems. The study results do show, however, the heterogeneity of steroid effects on the 
nervous system and behavior. This could indicate that effects found in humans may be dependent on the chemical structure of AASs. Clark et al. (1996) also studied the effect of AASs on brain reward using the rate frequency curve shift paradigm of brain stimulation reward in male rats that had electrodes implanted in the lateral hypothalamus. In the first of two studies, treatment for two weeks with 1 $\mathrm{mg} /$ day methandrostenolone had no effect on either the reward or performance components of intracranial self-stimulation. In the second study where the rats were treated for 15 weeks with 2 $\mathrm{mg} / \mathrm{kg}$ testosterone cypionate, $2 \mathrm{mg} / \mathrm{kg}$ nandrolone decanoate, and $1 \mathrm{mg} / \mathrm{kg}$ boldenone undecylenate, brain reward was also unaffected. However, a significant change was noted in the bar press rate. In the latter study, the rats also received a single injection of dexamphetamine before and after the 15 weeks of AAS exposure. The rate-frequency curve shift was significantly greater in animals after the 15 weeks of multiple steroid exposure. This would suggest that AAS may influence the sensitivity of the brain reward system.

In another study investigating the effect of high doses of testosterone on anticonflict behavior, tubing containing $200 \mathrm{mg}$ testosterone was implanted subcutaneously in the back of one group of male Wistar rats (Bing et al., 1998). Anticonflict behavior was tested eight weeks after implantation. Another group of male rats received a single subcutaneous injection of $5 \mathrm{mg} / \mathrm{kg}$ testosterone and were tested for anticonflict behavior 24 hours later. Relative to control rats included for both treatments, both groups—one receiving chronic and the other acute testosterone treatment-testosterone reduced impulse control and promoted aggression, thereby indicating that anticonflict behavior may reflect anxiolysis and reduced impulse control.

Bronson et al. (1996) investigated the effect of a combination of four steroids (testosterone, testosterone cypionate, methyl testosterone, and norethandrolone) given for nine weeks at either one or five times the androgenic maintenance dose for male mice to female mice. The study was conducted to examine the effects of AAS treatment on the behavior and physiological characteristics. Steroid treatment depressed gonadotropin secretion and increased the body weight and fat content. Treatment 
also decreased activity, increased aggressiveness as demonstrated by pair fighting, and eliminated sexual behavior. There was essentially no difference in the response of the mice to the dose of steroids given, suggesting that a threshold effect may have been present. In a related study, Bronson et al. (1996) treated adult male and female mice for six months with the same combination of steroids as used in the earlier study. Both male and female mice were given either 5 or 20 times the male mouse AAS's maintenance level. Treatment with the combination of steroids increased aggressiveness in the female mice but not in the males. 